Article

\title{
Neuroglobin: A New Possible Marker of Estrogen-Responsive Breast Cancer
}

\author{
Virginia Solar Fernandez ${ }^{1}$, Marco Fiocchetti ${ }^{1, *} * \mathbb{D}$, Manuela Cipolletti ${ }^{1} \mathbb{C}$, Marco Segatto $\left.{ }^{2} \mathbb{(}\right)$, Paolo Cercola ${ }^{3}$, \\ Annalisa Massari ${ }^{3}$, Sabrina Ghinassi ${ }^{3,+}$, Francesco Cavaliere $^{3}$ and Maria Marino ${ }^{1, *} \mathbb{C}$
}

1 Department of Science, University Roma Tre, Viale Guglielmo Marconi 446, I-00146 Roma, Italy; virginia.solarfernandez@uniroma3.it (V.S.F.); manuela.cipolletti@uniroma3.it (M.C.)

2 Department of Biosciences and Territory, University of Molise, Contrada Fonte Lappone, 86090 Pesche (IS), Italy; marco.segatto@unimol.it

3 Division of Senology, Belcolle Hospital, Str. Sammartinese, 01100 Viterbo, Italy; paolo.cercola@asl.vt.it (P.C.); annalisa.massari@asl.vt.it (A.M.); sabrinaghinassi@yahoo.it (S.G.); francesco.cavaliere@asl.vt.it (F.C.)

* Correspondence: marco.fiocchetti@uniroma3.it (M.F.); maria.marino@uniroma3.it (M.M.); Tel.: +39-06-5733-6455 (M.F.); +39-06-5733-6320 (M.M.); Fax: +39-06-5733-6321 (M.F. \& M.M.)

+ Present address: Santo Spirito in Sassia Hospital, Lungotevere in Sassia, 1, 00193 Roma, Italy.

Citation: Solar Fernandez, V.;

Fiocchetti, M.; Cipolletti, M.; Segatto,

M.; Cercola, P.; Massari, A.; Ghinassi,

S.; Cavaliere, F.; Marino, M.

Neuroglobin: A New Possible Marker of Estrogen-Responsive Breast Cancer. Cells 2021, 10, 1986. https://doi.org/ $10.3390 /$ cells10081986

Academic Editor: Satoshi Inoue

Received: 2 July 2021

Accepted: 4 August 2021

Published: 5 August 2021

Publisher's Note: MDPI stays neutral with regard to jurisdictional claims in published maps and institutional affiliations.

Copyright: (c) 2021 by the authors. Licensee MDPI, Basel, Switzerland. This article is an open access article distributed under the terms and conditions of the Creative Commons Attribution (CC BY) license (https:/ / creativecommons.org/licenses/by/ $4.0 /)$.
Abstract: The expression of the $\alpha$-subtype of Estrogen Receptor (ER $\alpha)$ characterizes most breast cancers (more than $75 \%$ ), for which endocrine therapy is the mainstay for their treatment. However, a high percentage of ER $\alpha+$ breast cancers are de novo or acquired resistance to endocrine therapy, and the definition of new targets for improving therapeutic interventions and the prediction of treatment response is demanding. Our previous data identified the ER $\alpha / A K T /$ neuroglobin (NGB) pathway as a common pro-survival process activated in different ER $\alpha$ breast cancer cell lines. However, no in vivo association between the globin and the malignity of breast cancer has yet been done. Here, we evaluated the levels and localization of NGB in ER $\alpha+$ breast ductal carcinoma tissue of different grades derived from pre-and post-menopausal patients. The results indicate a strong association between NGB accumulation, ER $\alpha$, AKT activation, and the G3 grade, while no association with the menopausal state has been evidenced. Analyses of the data set (e.g., GOBO) strengthen the idea that NGB accumulation could be linked to tumor cell aggressiveness (high grade) and resistance to treatment. These data support the view that NGB accumulation, mainly related to ER expression and tumor grade, represents a compensatory process, which allows cancer cells to survive in an unfavorable environment.

Keywords: AKT; breast cancer survival; ductal infiltrating adenocarcinoma; estrogen receptor $\alpha$; neuroglobin; tumor microenvironment

\section{Introduction}

Female breast cancer represents the most commonly diagnosed cancer among both sexes, with an estimated 2.3 million (11.3\% of total) new cases in 2020 [1]. Estrogen-receptor$\alpha$-positive $(\mathrm{ER} \alpha+)$ breast cancers represent $79 \%$ of the reported cases worldwide [2]. They refer to the expression of ER $\alpha$, the activation of which by $17 \beta$-Estradiol (E2) plays a pivotal role in inducing breast cancer cells' proliferation and survival $[3,4]$. Consistent with ER $\alpha$ activities in the development, progression, and treatment of breast cancer, the endocrine therapy is used in clinical practice to interfere with cancer cell growth and survival through the inhibition of E2 synthesis (aromatase inhibitors) or the antagonism of ER $\alpha$ activation (e.g., fulvestrant, tamoxifen) [4,5]. However, a high percentage of ER $\alpha+$ breast cancers are de-novo (15-20\%) or acquired resistance (30-40\%) to endocrine therapy progressing from hormone dependence to independence, although a functional ER $\alpha$ pathway is still maintained $[4,6,7]$. Therefore, basic studies shifted their interests on molecular mechanisms and mediators of ER $\alpha$ action to find alternative targets and new possible biomarkers to improve therapeutic interventions and the prediction of treatment response [6]. 
In such a context, we found a new compensatory protein named neuroglobin (NGB), which is up-regulated and re-allocated to mitochondria by E2 in ER $\alpha+$ breast cancer cells [8]. Since its discovery in neurons, NGB has attracted great research interest, in particular, because of its cytoprotective effect against several types of insults [9-14]. Consistent with this, our previous data define NGB accumulation as the key factor in the E2-activated ER $\alpha$ pathway devoted to breast cancer cell survival against oxidative stress and chemotherapeutic agents [8,15]. In addition, our recent findings further identified the ER $\alpha /$ AKT/NGB pathway as a common pro-survival process activated in different, ER $\alpha$-positive, breast cancer cells [16].

Notwithstanding this, the possible association between high levels of NGB and human cancer progression is still unclear and strongly debated [17-19]. On one hand, the enhanced expression of NGB in cancer cells and in the primary tumor of brain and non-brain origins (e.g., breast, lung) has been demonstrated and connected to the endogenous stress-related mechanism of cancer defense $[17,19]$. On other hand, a tumor suppression function for NGB accumulation has been proposed [20]. Finally, no expression of NGB mRNA in nonnervous tumors and normal organs [18] has been reported. These conflicting data, obtained with dissimilar approaches in different cancer tissues, could imply that a cellular/tissue context-dependent effect of NGB exists, highlighting the need to verify in vivo the possible connection between NGB accumulation and breast cancer progression. Here, the hypothesis that E2-induced NGB accumulation is a conserved compensatory mechanism important for breast cancer progression, by averting mitochondrial apoptosis, has been evaluated in $\mathrm{ER} \alpha$-expressing breast ductal carcinoma tissue samples with different grades derived from patients who were not subjected to chemotherapy or endocrine treatments earlier.

\section{Materials and Methods}

\subsection{Reagents}

Protease inhibitor cocktail, bovine serum albumin fraction V (BSA), phosphatase inhibitor cocktail, PBS, Tris buffer, anti-vinculin (clone hVIN-1, mouse monoclonal) antiNeuroglobin (clone 6G1.1, mouse monoclonal) were purchased from MERCK (Darmstadt, Germany), and polyclonal anti-NGB antibody from Santa Cruz Biotechnology (FL-151, Santa Cruz, CA, USA). Bradford protein assay was obtained from Bio-Rad Laboratories (Hercules, CA, USA). The anti-phospho-ER $\alpha$ (pER $\alpha$ Ser118, 16J4 mouse monoclonal) and anti-phospho-AKT (pAKT, 193H12, rabbit monoclonal) antibodies were purchased from Cell Signalling Technology Inc. (Beverly, MA, USA). Specific antibodies against ER $\alpha$ (HC20, rabbit polyclonal), Estrogen Receptor $\beta$ (ER $\beta, \mathrm{H}-150$ rabbit polyclonal), Bcl-2 (C-2, mouse monoclonal), Tumor necrosis factor receptor-associated protein 1 (TRAP-1, TR-1 mouse monoclonal), protein phosphatase 2A (PP2A, FL-309, rabbit polyclonal), G protein-coupled estrogen receptor 1 (GPER, N-15 rabbit polyclonal), and AKT (B-1, mouse monoclonal) were obtained from Santa Cruz Biotechnology (Santa Cruz, CA, USA). Chemiluminescence reagent for Western blot ECL was obtained from Bio-Rad (Hercules, CA, USA).

All the other products were obtained from MERCK. Analytical- or reagent-grade products were used without further purification.

\subsection{Human Subjects}

All followed procedures were in accordance with the Ethics Committee Lazio 1 Protocol number 2012/CE Lazio 1 and with the Helsinki Declaration of 1975 (World Medical Association Declaration of Helsinki 2000). Signed informed consent was obtained from all individual participants included in the study. Fifty-three women of different ages and types of ER-positive breast cancers (Table 1) were recruited in the study.

\subsection{Breast Cancer Tissues}

Surgical breast paraffin-embedded sections and cryo-conserved fresh tissue were collected at Belcolle Hospital in Viterbo from primary tumors and from normal tissue of patients who had undergone breast surgery. Based on the histopathological analysis of 
surgical specimens, we selected ER $\alpha+$ ductal carcinoma divided into G2 $(n=38)$ and G3 $(n=15)$. The G1 grade or well-differentiated represents only the $7 \%$ of the breast cancers with respect to the G2 (71\%, the most frequent) and G3 (22\%) grades. The cells of the G1 grade are slower growing and look more like normal breast tissue. This low frequency and high differentiation led us to increase the number of G2 and G3 specimens, avoiding G1 samples. In Table 1, the considered histopathological characteristics of patients are reported. All tissue samples were stored and conserved until use at $-80^{\circ} \mathrm{C}$.

Table 1. Histopathological characteristics of tumors of patients who had undergone breast surgery.

\begin{tabular}{|c|c|c|c|}
\hline \multicolumn{2}{|c|}{ Variable } & \multirow{2}{*}{$\begin{array}{c}\begin{array}{c}\text { Number of Patients } \\
\left(\mathbf{N}_{\text {TOT }}=53\right)\end{array} \\
38\end{array}$} & \multirow{2}{*}{$\begin{array}{c}\text { \% on Total Patients } \\
71.7\end{array}$} \\
\hline & Yes (Age $\geq 51$ years) & & \\
\hline Menopausal status & No (Age < 51 years) & 15 & 28.3 \\
\hline Hystological type & Ductal carcinoma & 53 & 100 \\
\hline ER/PR Status & Positive & 53 & 100 \\
\hline \multirow{2}{*}{ Grade } & $\mathrm{G} 2$ & 38 (26 Menopause Y; 12 Menopause N) & 71.7 \\
\hline & G3 & 15 (12 Menopause Y; 3 Menopause N) & 28.3 \\
\hline
\end{tabular}

\subsection{Breast Tissue Immunohistochemistry}

For immunohistochemistry analysis, $10 \mathrm{ER} \alpha+$ Grade 2 infiltrating ductal carcinoma were selected. Breast cancer paraffin-embedded sections were deparaffinized in HistoChoice Clearing Agent MERCK (Darmstadt, Germany) and rehydrated in a graded series of ethanol. For antigen retrieval, the sections were boiled in a microwave in $10 \mathrm{mM}$ of sodium citrate ( $\mathrm{pH}$ 6.0) for 3 min. The sections were incubated in $3.0 \% \mathrm{H}_{2} \mathrm{O}_{2}$ solution for 3 min to block endogenous peroxidase activity. Following a blocking step with 3\% BSA in PBS + Triton-X 100 0.5\%, the sections were incubated with the primary mouse monoclonal NGB (Clone 6G1.1 Merck, Figure 1 and Figure 4 ) o/n at $4{ }^{\circ} \mathrm{C}$. The possibility of non-specific staining has been excluded by using a polyclonal anti-NGB antibody (FL-151, Santa Cruz, CA, USA). After washing with PBS, sections were incubated with anti-mouse secondary antibody for $30 \mathrm{~min}$ at room temperature. Antibody binding was detected using a ImmPACT DAB Peroxidase Substrate Kit (Vector Laboratories Inc, Burlingame, CA, USA).

\subsection{Protein Extraction and Western Blot Assay}

Tissue fragments were cut into small pieces and then homogenized in 10 vol of YY buffer (50 mM HEPES at pH 7.5, 10\% glycerol, $150 \mathrm{mM} \mathrm{NaCl}$, 1\% Triton X-100, 1 mM EDTA, $1 \mathrm{mM}$ EGTA) containing $0.70 \%(w / v)$ SDS, with 65 strokes in a glass-Teflon homogenizer. Homogenates were centrifuged at $10,000 \times g$ for $10 \mathrm{~min}$. Supernatant was collected for Western blots. Total proteins were quantified using the Bradford Protein Assay. Solubilized proteins $(20 \mu \mathrm{g})$ were resolved by $7 \%, 10 \%$ or $15 \%$ SDS-PAGE at $100 \mathrm{~V}$ for $1 \mathrm{~h}$ at $24.0{ }^{\circ} \mathrm{C}$ and then transferred to nitrocellulose with the Trans-Blot Turbo Transfer System (Bio-Rad, Hercules, CA, USA) for 10 or $7 \mathrm{~min}$. The nitrocellulose was treated with filtered $5 \%(w / v)$ BSA in $138.0 \mathrm{mM} \mathrm{NaCl}, 25.0 \mathrm{mM}$ Tris, $\mathrm{pH} 8.0$, at $24.0^{\circ} \mathrm{C}$ for $1 \mathrm{~h}$ and then probed overnight at $4.0^{\circ} \mathrm{C}$ with either anti-NGB (mouse monoclonal Clone 6G1.1, final dilution 1:1000), anti-Bcl2 (final dilution 1:1000), anti-pER $\alpha$ (final dilution 1:1000), anti-ER $\beta$ (final dilution 1:1000), anti-GPER (final dilution 1:1000) and anti-pAKT (final dilution 1:1000). The nitrocellulose was stripped by the Restore Western Blot Stripping Buffer (Pierce Chemical, Rockford, IL, USA) for $30 \mathrm{~min}$ at room temperature and then probed with anti-ER $\alpha$ (final dilution 1:1000) or anti-AKT (final dilution 1:1000) or anti-vinculin (final dilution 1:30,000) to normalize the protein loading. 

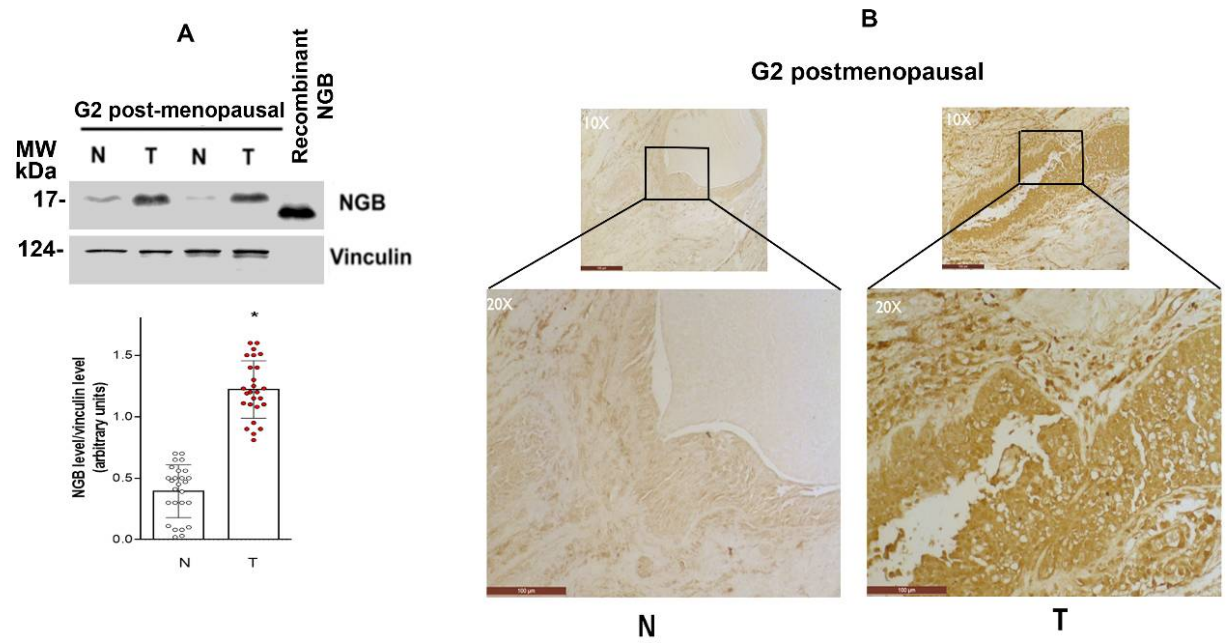

Figure 1. NGB levels in breast cancer tissue. Representative Western blot images of NGB protein levels (A) in two G2-grade post-menopausal specimens of breast cancer (T) and their normal counterpart $(\mathrm{N})$. The amount of protein was normalized by comparison with vinculin levels. A total of $5 \mathrm{ng}$ of recombinant NGB was used as protein standard. Data are the mean \pm SD of 26 tissues. * $p<0.001$ was calculated with Student's t-test with respect to normal tissues. (B) Representative immunohistochemical staining of NGB (mouse monoclonal Clone 6G1.1 anti-NGB MERCK) in 1 out of 10 breast G2-grade post-menopausal specimens of breast cancer (T) and normal counterpart (N). The scale bar is $100 \mu \mathrm{m} / \mathrm{cm}$. The black square refers to the below-reported optical magnification.

\subsection{Mitochondria Isolation}

Tissue fractionation was performed using the ApoAlert ${ }^{\mathrm{TM}}$ Cell Fractionation kit (Clontech Laboratories Inc. Mountain View, CA, USA) according to the manufacturer's instructions. Tissue fragments were cut into small pieces, washed with Wash buffer, suspended in Fractionation Buffer Mix containing DTT $1 \mathrm{mM}$ and then homogenized with 65 strokes in a glass-Teflon homogenizer. Homogenate was centrifuged at $700 \times g$ for $10 \mathrm{~min}$. The pellet was discarded and supernatant centrifuged at $10,000 \times g$ for $25 \mathrm{~min}$. The pellet (Mitochondrial fraction) was resuspended in YY buffer (50 mM HEPES at pH 7.5, 10\% glycerol, $150 \mathrm{mM} \mathrm{NaCl}$, 1\% Triton X-100, 1 mM EDTA, 1 mM EGTA) containing 4.0\% $(w / v)$ of SDS. Supernatant (cytosolic fraction) was collected in a separate tube. The protein concentration of each fraction was determined using Bradford protein assay. Lysate of each fraction was then processed for Western blot. The mitochondrial TRAP-1 and cytosolic PP2A were used as fraction purity markers.

\subsection{Statistical Analysis}

The statistical analysis was performed with ANOVA followed by Bonferroni post-test to compare multiple samples or with Student's $t$-test to compare two diverse samples by InStat 3.10 software system for Windows. In all cases, $p<0.05$ was considered significant.

\section{Results}

\subsection{NGB Expression in Breast Tumors}

Fifty-three Er $\alpha$-positive ductal carcinoma specimens $(\mathrm{T}=$ tumor) were obtained from 35-80-year-old patients and divided considering menopausal state (pre/post menopause) or the tumoral grade (G2, G3, divided in 38 and 15 samples respectively) (Table 1). Samples of non-proliferative ductal cells of the same patients were used as a control $(\mathrm{N}=$ normal) (see the Material and Method section for details). A significant accumulation of NGB in the G2 grade of post-menopausal patients compared to the normal counterpart is reported in Figure 1A. To further confirm the high level of NGB in breast cancer tissue, paraffinembedded sections of ER $\alpha+$ invasive ductal carcinoma grade G2 from 10 breast cancer patients and their healthy counterparts were subjected to immunohistochemistry staining 
against NGB. The NGB immunoreactivity is barely detectable in the normal tissue, whereas cancer samples show a strong positive NGB staining in the epithelial cells (Figure 1B and Supplementary Figure S1).

\subsection{Association between NGB and Estrogen Receptor Levels and Activities in Breast Tumors}

Clinical practice considers ER $\alpha+$ breast cancers those expressing this receptor subtype in the nucleus. Although all tumor tissues selected for this study were ER $\alpha+$, due to the heterogeneity of breast cancer, we would determine if the other subtype of estrogen receptor (e.g., ER $\beta$ ) as well as the seven uncanonical membrane-spanning estrogen receptor (e.g., GPER), were involved in NGB accumulation in cancer tissues. In addition, the activation status of $\operatorname{ER} \alpha$ (e.g., phosphorylation at Ser118, $\mathrm{pER} \alpha$ ), the Bcl-2 levels, an $\mathrm{E} 2 / \mathrm{ER} \alpha$-dependent apoptosis associated factor [21], and the activation of AKT, one of the ER $\alpha$-dependent signals important for NGB accumulation in cancer cell lines [16], have been evaluated in G2-grade tumors of pre-and post-menopausal patients. Figure 2A confirms that both pre-and post-menopausal tissues contain relevant levels of ER $\alpha$, but only in cancer tissues ER $\alpha$ is phosphorylated in Ser118 sustaining its activated status [22,23], which is higher in pre-menopausal than in post-menopausal samples. Consistent with the activation status of $\mathrm{ER} \alpha$, a high level of Bcl-2 protein and the increased phosphorylation of AKT is reported in cancer specimens when compared to the normal counterparts (Figure 2A,B, respectively). None of the other estrogen receptors is expressed at a relevant amount in cancer tissues. Indeed, ER $\beta$ is barely detected both in normal and cancer tissues, while GPER levels are lower in cancer tissues than in their normal counterparts (Figure 2A).

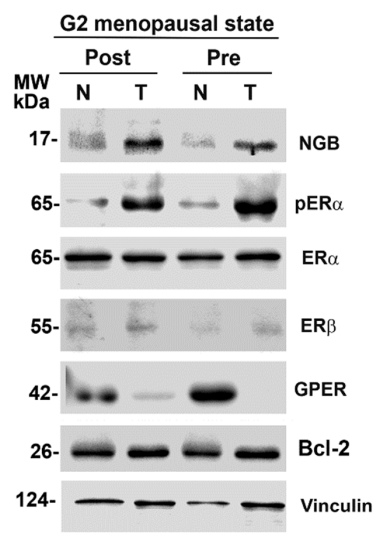

A
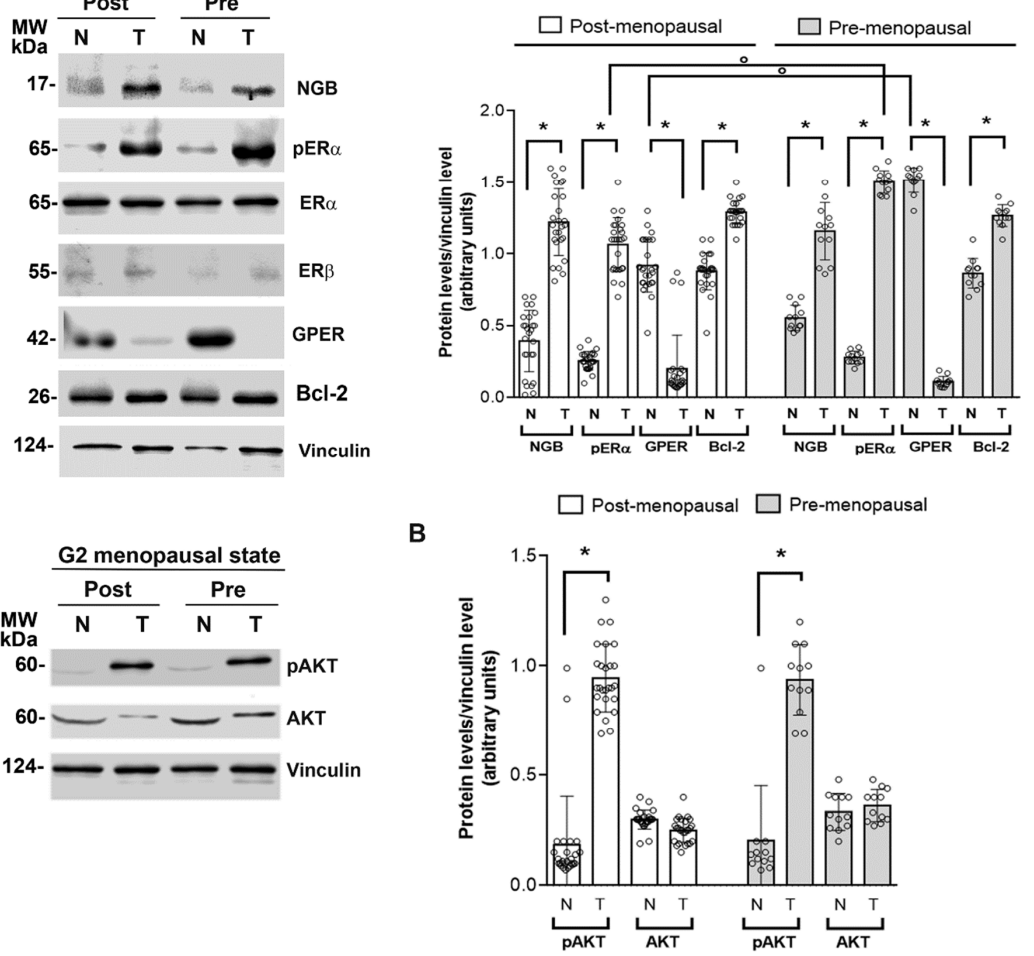

Figure 2. Association between NGB levels and estrogen receptors in breast cancer tissue. Representative Western blot images of NGB, $\mathrm{pER} \alpha, \mathrm{ER} \alpha, \mathrm{ER} \beta, \mathrm{GPER}, \mathrm{Bcl}-2$ protein levels (A) and AKT levels and activation $(\mathbf{B})$ in G2-grade post- $(n=26)$ and pre-menopausal $(n=12)$ specimens of breast cancer $(\mathrm{T})$ and their normal counterpart $(\mathrm{N})$. The amount of protein was normalized by comparison with vinculin levels. Data are the mean \pm SD. $p<0.001$ was calculated with Student's t-test with respect to the normal or tumoral (e.g., GPER) counterpart $\left(^{*}\right)$ and vs. the same parameter on the post-menopausal sample $\left(^{\circ}\right)$. 
In line with previous results obtained in breast cancer cells [24], high levels of NGB have been detected only in tumor samples versus their matched normal tissue, sustaining a key role of the globin in breast cancer pathophysiology.

\subsection{NGB Association with Tumor Grade}

To evaluate whether the levels of NGB could change with cancer progression, the globin expression has been assessed among tumor samples divided based on their stratification for the histological grade (G2 and G3; $n=38$ and $n=15$ respectively). A significantly high NGB accumulation in G3 tumor tissue, which represents the most aggressive grade with marked variability, is reported (Figure 3).

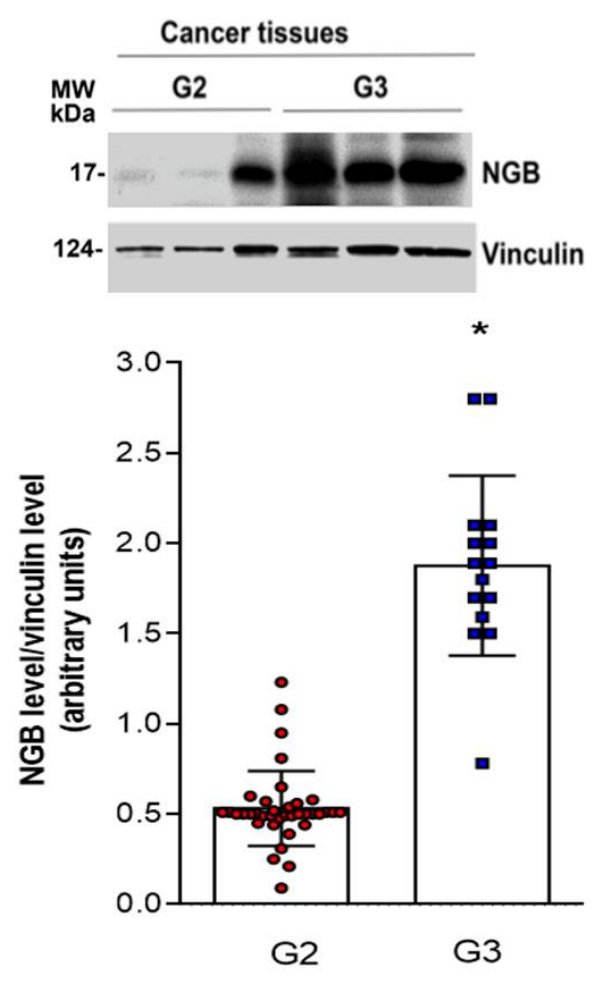

Figure 3. NGB protein levels in tumor samples of breast cancer patients. Representative Western blot images (upper panel) of tissue levels of NGB from G2 and G3 samples and correspondent densitometric analysis of all analyzed tissues ( $n=38, n=15$, respectively) (bottom panel). The amount of protein was normalized by comparison with vinculin levels. Data are means \pm SD. $p<0.01$ was determined with ANOVA followed by Bonferroni post-test vs. G2 $\left.{ }^{*}\right)$ samples.

\subsection{NGB Localization in Breast Cancer Tissues}

As reported above, the increase in NGB levels induced by E2, via ER $\alpha$ and AKT activation, plays an anti-apoptotic effect when the globin is accumulated into the mitochondria of breast cancer cells [16]. This evidence prompted us to study the compartmentalization of NGB in the cytosolic and mitochondrial fractions of G2 and G3 samples. TNF receptor-associated protein 1 (TRAP1) and the protein phosphatase 2A (PP2A) were used as fractionation purity markers of the mitochondrial and cytosolic fraction, respectively. Due to the low levels of expressed NGB (Figure 1), no NGB reactivity was reported in the cytosolic and mitochondrial fraction of normal tissues (data not shown), whereas a significant accumulation of NGB was reported not only in the cytosol, but also in the mitochondrial fraction of cancer tissues (Figure 4A). The ductal carcinoma of G3-grade tissue showed a higher NGB immunoreactivity compared to G2 tissues in both whole lysate and subcellular fraction (Figure 4A). Thus, at least two different pools of NGB, cytosolic and mitochondrial, exist in the breast tissues and they can act to preserve cancer cell survival and resistance to environmental stresses. Moreover, immunohistochemical analysis of G2 
breast cancer tissues revealed strong NGB staining near the border of the duct close to the lumen, sustaining the idea of a possible accumulation of NGB on the cell periphery (Figure 4B).

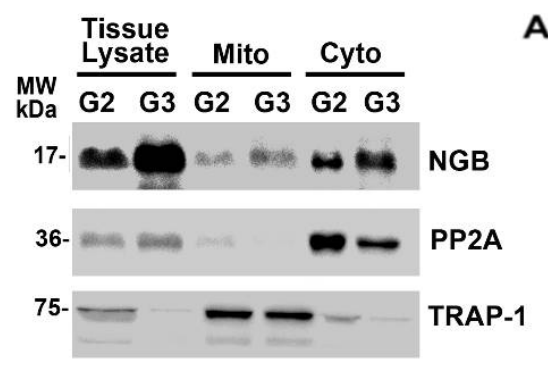

A

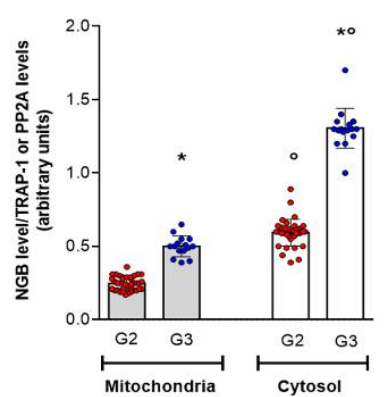

B

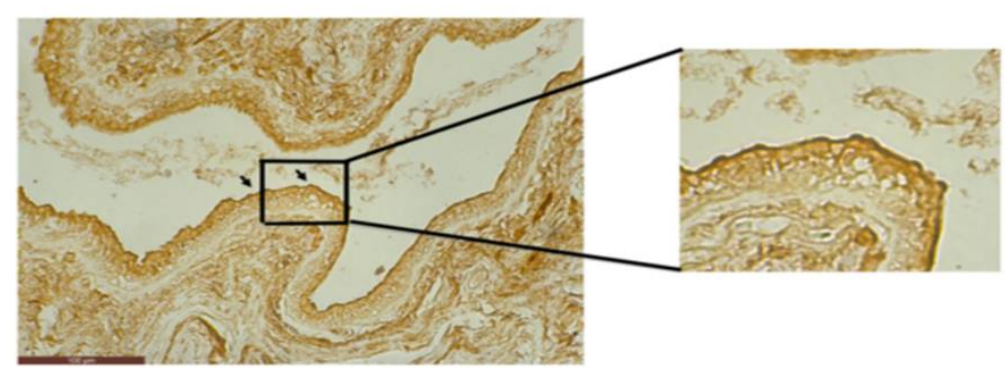

Figure 4. NGB localization in breast tissues. (A) Representative Western blot image (left panel) of NGB levels in whole tissue (Tissue lysate) and in subcellular (Mitochondria-Mito, Cytosol-Cyto) fractions of G2 and G3 samples and densitometric analysis (right panel) of NGB levels in subcellular fractions among all available tissues (G2 $n=38$, G3 $n=15$, respectively). The amount of protein was normalized by comparison with the cytosolic marker protein phosphatase $2 \mathrm{~A}(\mathrm{PP} 2 \mathrm{~A})$ and the mitochondrial marker tumor necrosis factor-associated protein 1 (TRAP-1). Data are means \pm SD. $p<0.01$ was determined with ANOVA followed by Bonferroni post-test vs. G2 $\left(^{*}\right)$ samples and vs. correspondent mitochondrial fraction $\left(^{\circ}\right)$. (B) Representative image shows positive NGB staining (mouse monoclonal Clone 6G1.1 anti-NGB MERCK) in the epithelial cells of the tumoral section in a G2 ER $\alpha+$ breast cancer tissue sample (total $n=10$ ). The scale bar is $100 \mu \mathrm{m} / \mathrm{cm}$. The black square refers to image detail reported on the right as a digital magnification.

\subsection{Effect of NGB Expression in Breast Cancer Patient Survival}

The results reported here showing the association between NGB accumulation and $\mathrm{ER} \alpha+$ ductal carcinoma tissues could sustain the promise of improving prognostication and treatment decisions for breast cancer patients. However, the heterogeneity of breast cancer emphasizes the need for validation of relative gene in larger sample sets stratified into relevant subgroups. Recently, a multifunctional online tool, GOBO (http: / / co.bmc.lu. se/gobo. Last access 4 August 2021), has been described [25]. GOBO allows for a range of different analyses to be performed in an 1881-sample breast tumor data set, and a 51-sample breast cancer cell line set, both generated on Affymetrix U133A microarrays. By using the GOBO data set, we analyzed the possible association between NGB gene (ID = 58157) expression levels with Overall Survival (OS) and Relapse-Free Survival (RFS) outcomes in G1, G2, and G3 subgroups of ER $\alpha+$ breast cancer data set. In Figure 5, Kaplan-Meier analysis shows positive differences regarding OS between high- or low-NGB-expressing tumor samples in the G1 grade, which was attenuated in G2-grade patients. Although not statistically significant, this positive difference was found to be reverted in G3-grade patients: notably, OS is lower in a high-NGB-expressing tumor (red line) when compared to the low-NGB-expressing patients after three years (gray line). Moreover, high-NGBexpressing tumor samples of G3 patients have a high significant ( $p=0.001$; Figure 5) lower 10-year RFS with respect to the low-expressing samples. 


\section{Overall survival (OS)}

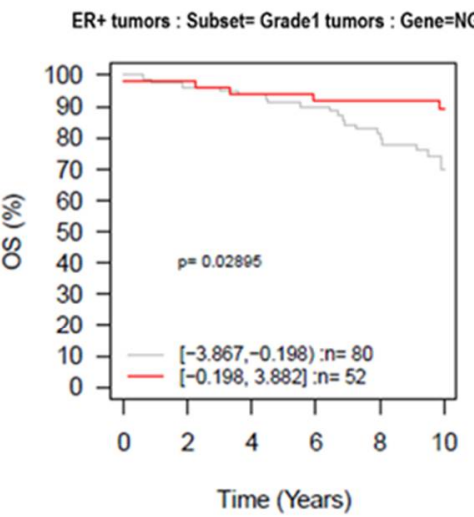

ER+ tumors : Subset= Grade2 tumors : Gene $=$ NGB

ER+ tumors : Subset= Grade3 tumors : Gene=NGB
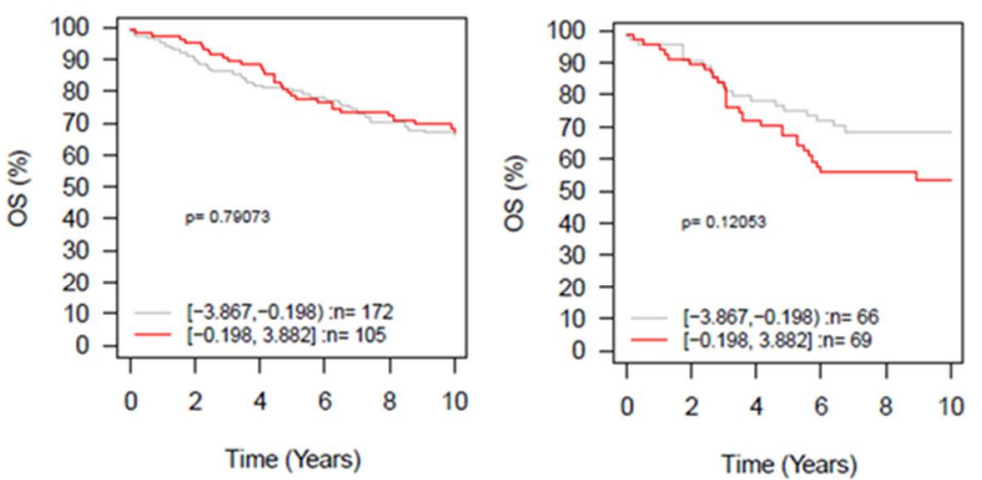

Relapse Free Survival (RFS)

ER+ tumors : Subset= Grade1 tumors : Gene=NGB

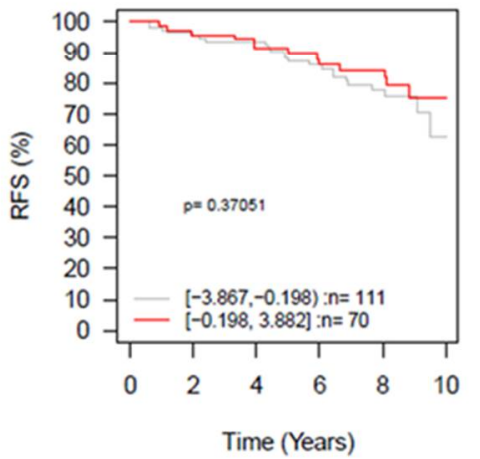

ER+ tumors : Subset= Grade2 tumors : Gene $=$ NGB

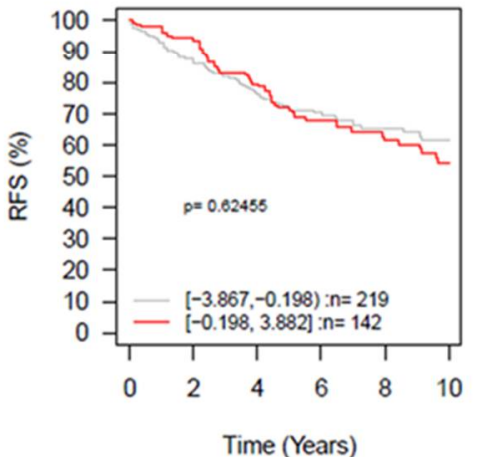

ER+ tumors : Subset= Grade 3 tumors : Gene=NGB

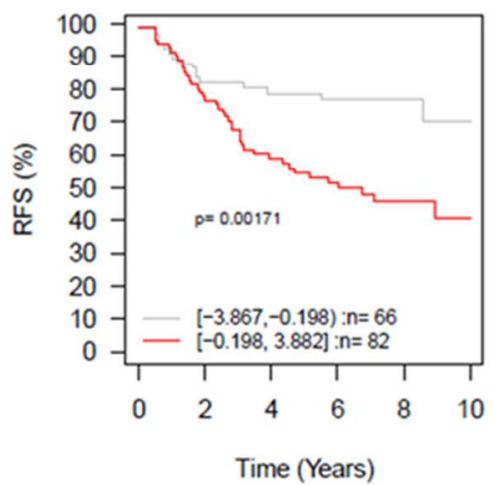

Figure 5. Data set analysis of survival in patients with different NGB expressions. Kaplan-Meier plots of high (red line) or low (gray line) NGB-expressing tumor samples (ID = 58157) available in the GOBO (Gene expression-based Outcome for Breast cancer Online). The data have been selected from ER $\alpha+$ samples based on tumor grade (lowest at left, highest at right). The overall (upper panels) and the relapse-free (bottom panels) survival have been selected as outcomes.

\section{Discussion}

Since its discovery in neurons, NGB has attracted great research interest, particularly because of its cytoprotective effects against several types of insults [26]. Although the expression of NGB has been found in both normal and cancerous extra-nervous tissues $[17,19]$, the correlation between NGB and human cancer is still unclear and strongly debated principally because other studies affirm that no significant levels of NGB transcript could be detected in extra-nervous cancers and normal tissues [18]. Despite the reported discrepancies, our previous findings define NGB as an E2-inducible protein in ER $\alpha+$ breast cancer cell models (MCF-7, T47D, ZR51), which accumulation is part of the E2-induced pathway devoted to the survival of breast cancer against stress injuries of a different nature $[8,24]$. Although cell line models are useful to define molecular candidates as markers of malignant transformation, several differences exist between cell lines and primary tumors. Indeed, the absence of any stromal and extracellular interaction and the selective pressure in cell culture could explain why several aspects of primary cancer biology are not fully represented by cancer cell systems [27]. This evidence prompted us to evaluate if the NGB accumulation reported in cancer cells is a conserved compensatory mechanism important for $\mathrm{ER} \alpha+$ ductal carcinoma progression.

Our data indicate that NGB is greatly accumulated in all breast tumor samples analyzed with respect to their normal counterparts, where the protein levels are barely detected. 
Remarkably, in line with the previous data reported on cell lines [8,24], the NGB buildup positively associates with the active status of $\mathrm{ER} \alpha$ (i.e., phosphorylation at Ser118) [22,23] and to the E2-inducible Bcl-2 accumulation and AKT activation [15]. Surprisingly, despite the dramatic decrease in circulating E2 in post-menopausal women, the levels of NGB did not change between pre-and post-menopausal cancer samples or in the activation of ER $\alpha$ or AKT. This is in line with the observation that breast cancer cells maintain an E2 concentration 10-20-fold higher than its corresponding plasma levels due to E2 uptake from surrounding tissues that include adipose tissue [28-30] in which the hormone synthesis occurs starting from steroidogenic precursors. The absence of any association between NGB accumulation in breast cancer tissues and other estrogen receptors (e.g., ER $\beta$ and GPER) strongly sustains the results obtained in cancer cell lines confirming the pivotal involvement of the ER $\alpha$ /AKT pathway in NGB accumulation in breast cancer tissues. Although the literature on isoform-specific roles of AKT in cancer progression is still debated, the three functional AKTs encoded by distinct genes are all differently involved in cancer growth and progression (AKT1), survival (AKT1 and AKT3), as well as in metastasis, migration, and invasion (AKT2) [31]. In cancer cell lines, we demonstrated that membrane-bound Er $\alpha$ induces the rapid and persistent activation of PI3K-AKT [32], thus leading, among other effects, to the block of NGB degradation, the increase in NGB gene transcription via CREB, and NGB translocation to the mitochondria, which culminate in breast cancer survival against oxidative stress and the apoptosis prevention $[15,16]$. The association here reported between ER $\alpha$ phosphorylation, AKT activation, and NGB accumulation strongly sustain that a similar pathway is also active in ER $\alpha+$ ductal carcinoma tissues.

A good association between NGB accumulation and the grades of the tumor samples was highlighted. Indeed, G3 breast cancer samples expressed significantly higher levels of the globin compared to G2 samples. G3 tumors show a lower degree of cell differentiation, a higher rate of proliferation/metastatization, and the worst outcome with respect to the other grades, which are much less aggressive [33]. The presence of high NGB levels in the highest-grade breast cancers can explain, at least in part, their bad prognosis. Indeed, since the well-known cytoprotective effect of NGB against several types of insults including oxidative stress and chemotherapy $[8,15,16]$, it may be thought that intracellular NGB accumulation would participate in the resistance mechanisms established by cancer cells to cope against tumor micro-environmental stress, which favor the G3 cancer aggressiveness. On the other side, data reported here could define NGB as a possible new prognostic marker for the disease. Indeed, markers regarding the specific grade of breast cancer have not yet been identified to date. Our result indicates that NGB tissue analysis could represent a good biomarker index for breast-cancer-grade identification and the subsequent treatment evaluation.

Historically, NGB accumulation in the cytosolic fraction has been associated with the regulation of several cell functions. NGB behaves as a direct scavenger of harmful excess in ROS and RNS, it acts as an upstream regulator of the intracellular signaling by activating the PI3K/AKT pathway or blocking the GDP dissociation from heterotrimeric G $\alpha$ protein, and NGB can directly inhibit the apoptosome formation by reducing, through a cytosolic reaction, the cytochrome $\mathrm{c}$, rendering it apoptotically inactive ([14] and therein citations). Accumulating evidence indicates that NGB is also physically and functionally associated with mitochondria. NGB overexpression preserves mitochondria ATP production, reduces ROS generation, and prevents mitochondria-mediated cell death signaling caused by physiological stressors [34]. Beyond the well-defined NGB mitochondria-associated function in neuron-derived cells, our previous data $[8,24]$ clearly show that E2 re-localized the NGB to the mitochondrial compartment also in breast cancer cell models (MCF-7, T47D), making the globin able to exert its anti-apoptotic activities [8]. Present findings indicate, for the first time, that NGB buildup is mainly localized in the cytosol of samples, even though a significant amount of the globin is also gathered in mitochondria of tumor tissue specimens. Consistently with the high expression of NGB at a higher tumor grade, we 
observed an increase in NGB levels both in the mitochondrial and cytosolic compartments in G3 specimens if compared to G2. To complicate further the scenario about the functional role of NGB in breast tumors, we demonstrated that a great immunoreactivity of NGB is localized near the border of the duct close to the lumen. Recently, the co-localization of NGB with collagen I fibers at the extracellular levels has been reported in breast tissues [35], supporting the idea of an in vivo secretion of the protein to the extracellular matrix by breast cancer cells. In the future, the analysis of NGB levels in the serum of breast cancer patients, with respect to comparable healthy volunteers, could reinforce from one side the possibility that NGB can have an extracellular function and from the other that, beyond the tissue levels of NGB, the amount of serum NGB can be used as a breast cancer biomarker with a prognostic value.

The research on the association between human cancer and globins (e.g., MB, cytoglobin, CYGB) has grown in the last years. In this context, the CYGB mRNA expression has been found downregulated in breast and lung carcinoma tissues with respect to the normal counterpart [18], and evidence suggested a tumor suppressor role for this globin [36,37]. Indeed, the overexpression and/or the induction of CYGB in breast cancer cell lines correlates with the reduction of cell migration and increased cell death [38]. Despite this, the levels of CYGB and NGB proteins were reported to generally be increased in different tumor sections in comparison to levels observed in corresponding normal tissues, leading the authors to suggest a contribution of both globins in promoting cancer survival under oxidative stress [17]. Additionally, MB expression has been reported in several epithelial cancers [39]. In breast cancer, MB levels have been correlated with luminal- ER $\alpha+$ subtype and with favorable prognostic outcomes in both ER $\alpha+$ and ER $\alpha$-breast cancers [40]. However, contrarily to NGB, the GOBO analysis did not show any significant correlation between $M B$ expression and Relapse-Free Survival (RFS) outcomes in the G1, G2, and G3 subgroups of the ER $\alpha+$ breast cancer data set (available at http:/ / co.bmc.lu.se/gobo. Last access 4 August 2021). In the scenario of a possible correlation between globins function in breast cancer cells, the data of an opposite link between the MB expression [41] or NGB levels $([8,15,16,35]$, and results reported here) and ER $\alpha$ activation is particularly interesting. Indeed, in line with the proposed tumor-suppressive function of $\mathrm{MB}$, the levels of this protein are downregulated by the E2/ER $\alpha$ pathways in cell culture [41], supporting a possible MB role in counteracting the Er $\alpha$-mediated function including cell growth and resistance to chemotherapeutic drugs [41-43]. On the other hand, the role of NGB as a target protein and mediator of the anti-apoptotic and anti-oxidant effect of the E2/ER $\alpha$ signaling $[8,15,16,44]$, along with the connection between ER $\alpha$ activation and NGB in vivo (present paper), corroborates the idea that among the different globins, NGB could represent that involved in tumor resistance and relapse, the overexpression of which, dependently or independently from estrogen signaling, can favor cancer cell survival and, potentially, tumor aggressiveness. Present and previous results draw possible multi-point and functional intersections between the globins in human cancers whose further analysis will be necessary and could be promising for defining the role of each protein and/or the prognostic/predictive value of the "dance" of the globins across human cancers.

Overall, our results converge on the accumulation of NGB as a novel characteristic of ER $\alpha+$ ductal carcinoma of Grade 3 that could be used for improving prognostication and treatment decisions for breast cancer patients. Indeed, the role played by NGB accumulation in cancer cell lines strongly sustains that this globin could increase the resilience of cancer cells against oxidative stress, nutrient deprivation, and chemotherapeutic treatment affecting the triggering of apoptosis as well as increasing cell responses to stress $[8,15,24,35,45]$. However, as mentioned previously, the heterogeneity of breast cancer emphasizes the need to validate a promising protein and/or its relative gene in larger sample sets stratified into relevant subgroups. Here, we used a multifunctional online tool, GOBO (http:/ / co.bmc.lu.se/gobo. Last access 4 August 2021) [25], that allows a range of different analyses to be performed in an 1881-sample breast tumor data set. The obtained results indicate a positive correlation between NGB gene expression and a lower 
RFS in the subset of Grade 3 tumors. These data support the hypothesis that the increased expression of NGB could be linked to tumor cell resistance to treatment mainly related to ER expression and tumor grade.

\section{Conclusions}

Taken together, these results reveal strong evidence of similarities between NGB behavior in the cancer cells' system and primary breast cancer tissues, strengthening the idea that NGB represents a compensatory protein, which allows cancer cells to survive in an unfavorable environment. The NGB unique expression in cancer tissue, relative to the normal counterpart, its anti-apoptotic role [8], and its involvement in breast cancer insensitivity to chemotherapeutic agents (e.g., paclitaxel) [15], introduces new insights in breast cancer research, supporting the possible role of NGB as a new biomarker of breast malignant transformation and as a target for clinical interventions. Therefore, in the light of reported results that provide evidence of the existence of at least three different pools of the globin (mitochondrial, cytosolic, and extracellular), research is still needed to clarify the mechanisms underlying the mitochondrial translocation of the protein and its extra-mitochondrial function under E2 stimulation and to explore a possible NGB release and its functions.

Supplementary Materials: The following are available online at https:/ /www.mdpi.com/article/ 10.3390/cells10081986/s1, Supplementary Figure S1 and the original images for Western blot have been uploaded with the manuscript.

Author Contributions: Conceptualization, M.M. and M.F.; methodology, S.G., F.C., A.M., M.S., M.F., M.M.; formal analysis, V.S.F., M.C., M.S., M.F., A.M.; resources, F.C., M.M.; data curation, M.F., M.M.; writing—original draft preparation, M.M.; writing—review and editing, V.S.F., M.C., M.S., M.F., F.C., S.G., P.C.; funding acquisition, M.M., M.F. All authors have read and agreed to the published version of the manuscript.

Funding: This work was supported by a grant from Associazione Italiana Ricerca sul Cancro (AIRC, IG\#15221) and PRIN 2017 n $^{\circ}$ 2017SNRXH3 to M.M. The grant of Excellence Departments, MIUR (Legge 232/2016, Articolo 1, Comma 314-337) to M.M. and M.F., is gratefully acknowledged.

Institutional Review Board Statement: The study was conducted according to the guidelines of the Declaration of Helsinki and approved by the Ethics Committee Lazio 1 Protocol number 2012/CE Lazio 1.

Informed Consent Statement: Informed consent was obtained from all subjects involved in the study. Written informed consent has been obtained from the patient(s) to publish this paper.

Conflicts of Interest: The authors declare that they have no conflict of interest.

\section{References}

1. Sung, H.; Ferlay, J.; Siegel, R.L.; Laversanne, M.; Soerjomataram, I.; Jemal, A.; Bray, F. Global Cancer Statistics 2020: GLOBOCAN Estimates of Incidence and Mortality Worldwide for 36 Cancers in 185 Countries. CA A Cancer J. Clin. 2021, 71, 209-249. [CrossRef] [PubMed]

2. DeSantis, C.E.; Ma, J.; Gaudet, M.M.; Newman, L.A.; Miller, K.D.; Sauer, A.G.; Jemal, A.; Siegel, R.L. Breast Cancer Statistics, 2019. CA A Cancer J. Clin. 2019, 69, 438-451. [CrossRef]

3. Acconcia, F.; Marino, M. The Effects of $17 \mathrm{~b}$-Estradiol in Cancer Are Mediated by Estrogen Receptor Signaling at the Plasma Membrane. Front. Physiol. 2011, 2, 30. [CrossRef] [PubMed]

4. Skandalis, S.S.; Afratis, N.; Smirlaki, G.; Nikitovic, D.; Theocharis, A.D.; Tzanakakis, G.N.; Karamanos, N.K. Cross-Talk between Estradiol Receptor and EGFR/IGF-IR Signaling Pathways in Estrogen-Responsive Breast Cancers: Focus on the Role and Impact of Proteoglycans. Matrix Biol. 2014, 35, 182-193. [CrossRef] [PubMed]

5. Vuong, D.; Simpson, P.T.; Green, B.; Cummings, M.C.; Lakhani, S.R. Molecular Classification of Breast Cancer. Virchows Arch. 2014, 465, 1-14. [CrossRef]

6. Lei, J.T.; Anurag, M.; Haricharan, S.; Gou, X.; Ellis, M.J. Endocrine Therapy Resistance: New Insights1. Breast 2019, 48, S26-S30. [CrossRef]

7. Murphy, L.C.; Seekallu, S.V.; Watson, P.H. Clinical Significance of Estrogen Receptor Phosphorylation. Endocr. Relat. Cancer 2011, 18, R1-R14. [CrossRef] [PubMed] 
8. Fiocchetti, M.; Nuzzo, M.T.; Totta, P.; Acconcia, F.; Ascenzi, P.; Marino, M. Neuroglobin, a pro-Survival Player in Estrogen Receptor $\alpha$-Positive Cancer Cells. Cell Death Dis. 2014, 5, e1449. [CrossRef] [PubMed]

9. Fordel, E.; Thijs, L.; Martinet, W.; Lenjou, M.; Laufs, T.; Van Bockstaele, D.; Moens, L.; Dewilde, S. Neuroglobin and Cytoglobin Overexpression Protects Human SH-SY5Y Neuroblastoma Cells against Oxidative Stress-Induced Cell Death. Neurosci. Lett. 2006, 410, 146-151. [CrossRef] [PubMed]

10. Greenberg, D.A.; Jin, K.; Khan, A.A. Neuroglobin: An Endogenous Neuroprotectant. Curr. Opin. Pharmacol. 2008, 8, 20-24. [CrossRef]

11. Khan, A.A.; Wang, Y.; Sun, Y.; Mao, X.O.; Xie, L.; Miles, E.; Graboski, J.; Chen, S.; Ellerby, L.M.; Jin, K.; et al. NeuroglobinOverexpressing Transgenic Mice Are Resistant to Cerebral and Myocardial Ischemia. Proc. Natl. Acad. Sci. USA 2006, 103, 17944-17948. [CrossRef]

12. Sun, Y.; Jin, K.; Mao, X.O.; Zhu, Y.; Greenberg, D.A. Neuroglobin Is Up-Regulated by and Protects Neurons from Hypoxic-Ischemic Injury. Proc. Natl. Acad. Sci. USA 2001, 98, 15306-15311. [CrossRef]

13. Yu, Z.; Liu, N.; Liu, J.; Yang, K.; Wang, X. Neuroglobin, a Novel Target for Endogenous Neuroprotection against Stroke and Neurodegenerative Disorders. Int. J. Mol. Sci. 2012, 13, 6995-7014. [CrossRef] [PubMed]

14. Ascenzi, P.; di Masi, A.; Leboffe, L.; Fiocchetti, M.; Nuzzo, M.T.; Brunori, M.; Marino, M. Neuroglobin: From Structure to Function in Health and Disease. Mol. Asp. Med. 2016, 52, 1-48. [CrossRef]

15. Fiocchetti, M.; Cipolletti, M.; Leone, S.; Ascenzi, P.; Marino, M. Neuroglobin Overexpression Induced by the 17 $\beta$-EstradiolEstrogen Receptor- $\alpha$ Pathway Reduces the Sensitivity of MCF-7 Breast Cancer Cell to Paclitaxel. IUBMB Life 2016, 68, 645-651. [CrossRef]

16. Fiocchetti, M.; Cipolletti, M.; Ascenzi, P.; Marino, M. Dissecting the 17 $\beta$-Estradiol Pathways Necessary for Neuroglobin AntiApoptotic Activity in Breast Cancer. J. Cell. Physiol. 2018, 233, 5087-5103. [CrossRef] [PubMed]

17. Emara, M.; Turner, A.R.; Allalunis-Turner, J. Hypoxic Regulation of Cytoglobin and Neuroglobin Expression in Human Normal and Tumor Tissues. Cancer Cell Int. 2010, 10, 33. [CrossRef]

18. Gorr, T.A.; Wichmann, D.; Pilarsky, C.; Theurillat, J.-P.; Fabrizius, A.; Laufs, T.; Bauer, T.; Koslowski, M.; Horn, S.; Burmester, T.; et al. Old Proteins-New Locations: Myoglobin, Haemoglobin, Neuroglobin and Cytoglobin in Solid Tumours and Cancer Cells. Acta Physiol. 2011, 202, 563-581. [CrossRef]

19. Oleksiewicz, U.; Daskoulidou, N.; Liloglou, T.; Tasopoulou, K.; Bryan, J.; Gosney, J.R.; Field, J.K.; Xinarianos, G. Neuroglobin and Myoglobin in Non-Small Cell Lung Cancer: Expression, Regulation and Prognosis. Lung Cancer 2011, 74, 411-418. [CrossRef]

20. Zhang, J.; Lan, S.J.; Liu, Q.R.; Liu, J.M.; Chen, X.Q. Neuroglobin, a Novel Intracellular Hexa-Coordinated Globin, Functions as a Tumor Suppressor in Hepatocellular Carcinoma via Raf/MAPK/Erk. Mol. Pharm. 2013, 83, 1109-1119. [CrossRef] [PubMed]

21. Martin, L.-A.; Dowsett, M. BCL-2: A New Therapeutic Target in Estrogen Receptor-Positive Breast Cancer? Cancer Cell 2013, 24, 7-9. [CrossRef] [PubMed]

22. Acconcia, F.; Kumar, R. Signaling Regulation of Genomic and Nongenomic Functions of Estrogen Receptors. Cancer Lett. 2006, 238, 1-14. [CrossRef] [PubMed]

23. Medunjanin, S.; Hermani, A.; De Servi, B.; Grisouard, J.; Rincke, G.; Mayer, D. Glycogen Synthase Kinase-3 Interacts with and Phosphorylates Estrogen Receptor $\alpha$ and Is Involved in the Regulation of Receptor Activity. J. Biol. Chem. 2005, 280, 33006-33014. [CrossRef]

24. Fiocchetti, M.; Cipolletti, M.; Marino, M. Compensatory Role of Neuroglobin in Nervous and Non-Nervous Cancer Cells in Response to the Nutrient Deprivation. PLoS ONE 2017, 12, e0189179. [CrossRef]

25. Ringnér, M.; Fredlund, E.; Häkkinen, J.; Borg, Å.; Staaf, J. GOBO: Gene Expression-Based Outcome for Breast Cancer Online. PLoS ONE 2011, 6, e17911. [CrossRef] [PubMed]

26. Fiocchetti, M.; Cracco, P.; Montalesi, E.; Solar Fernandez, V.; Stuart, J.A.; Marino, M. Neuroglobin and Mitochondria: The Impact on Neurodegenerative Diseases. Arch. Biochem. Biophys. 2021, 701, 108823. [CrossRef]

27. Neve, R.M.; Chin, K.; Fridlyand, J.; Yeh, J.; Baehner, F.L.; Fevr, T.; Clark, L.; Bayani, N.; Coppe, J.-P.; Tong, F.; et al. A Collection of Breast Cancer Cell Lines for the Study of Functionally Distinct Cancer Subtypes. Cancer Cell 2006, 10, 515-527. [CrossRef]

28. Ali, H.; Rousseau, J.; Gantchev, T.G.; van Lier, J.E. 2- and 4-Fluorinated 16.Alpha.-[125I]Iodoestradiol Derivatives: Synthesis and Effect on Estrogen Receptor Binding and Receptor-Mediated Target Tissue Uptake. J. Med. Chem. 1993, 36, 4255-4263. [CrossRef]

29. Geisler, J. Breast Cancer Tissue Estrogens and Their Manipulation with Aromatase Inhibitors and Inactivators. J. Steroid Biochem. Mol. Biol. 2003, 86, 245-253. [CrossRef]

30. Savolainen-Peltonen, H.; Vihma, V.; Leidenius, M.; Wang, F.; Turpeinen, U.; Hämäläinen, E.; Tikkanen, M.J.; Mikkola, T.S. Breast Adipose Tissue Estrogen Metabolism in Postmenopausal Women With or Without Breast Cancer. J. Clin. Endocrinol. Metab. 2014, 99, E2661-E2667. [CrossRef]

31. Khatpe, A.S.; Adebayo, A.K.; Herodotou, C.A.; Kumar, B.; Nakshatri, H. Nexus between PI3K/AKT and Estrogen Receptor Signaling in Breast Cancer. Cancers 2021, 13, 369. [CrossRef] [PubMed]

32. Acconcia, F.; Totta, P.; Ogawa, S.; Cardillo, I.; Inoue, S.; Leone, S.; Trentalance, A.; Muramatsu, M.; Marino, M. Survival versus Apoptotic 17 $\beta$-Estradiol Effect: Role of ER $\alpha$ and ER $\beta$ Activated Non-Genomic Signaling. J. Cell. Physiol. 2005, 203, 193-201. [CrossRef] [PubMed] 
33. Ivshina, A.V.; George, J.; Senko, O.; Mow, B.; Putti, T.C.; Smeds, J.; Lindahl, T.; Pawitan, Y.; Hall, P.; Nordgren, H.; et al. Genetic Reclassification of Histologic Grade Delineates New Clinical Subtypes of Breast Cancer. Cancer Res. 2006, 66, 10292-10301. [CrossRef]

34. Yu, Z.; Poppe, J.L.; Wang, X. Mitochondrial Mechanisms of Neuroglobin's Neuroprotection. Oxidative Med. Cell. Longev. 2013, 2013, e756989. [CrossRef] [PubMed]

35. Fiocchetti, M.; Solar Fernandez, V.; Segatto, M.; Leone, S.; Cercola, P.; Massari, A.; Cavaliere, F.; Marino, M. Extracellular Neuroglobin as a Stress-Induced Factor Activating Pre-Adaptation Mechanisms against Oxidative Stress and ChemotherapyInduced Cell Death in Breast Cancer. Cancers 2020, 12, 2451. [CrossRef] [PubMed]

36. Shivapurkar, N.; Stastny, V.; Okumura, N.; Girard, L.; Xie, Y.; Prinsen, C.; Thunnissen, F.B.; Wistuba, I.I.; Czerniak, B.; Frenkel, E.; et al. Cytoglobin, the Newest Member of the Globin Family, Functions as a Tumor Suppressor Gene. Cancer Res. 2008, 68, 7448-7456. [CrossRef]

37. Bholah, T.C.; Neergheen-Bhujun, V.S.; Hodges, N.J.; Dyall, S.D.; Bahorun, T. Cytoglobin as a Biomarker in Cancer: Potential Perspective for Diagnosis and Management. BioMed Res. Int. 2015, 2015, e824514. [CrossRef]

38. Rowland, L.K.; Campbell, P.S.; Mavingire, N.; Wooten, J.V.; McLean, L.; Zylstra, D.; Thorne, G.; Daly, D.; Boyle, K.; Whang, S.; et al. Putative Tumor Suppressor Cytoglobin Promotes Aryl Hydrocarbon Receptor Ligand-Mediated Triple Negative Breast Cancer Cell Death. J. Cell. Biochem. 2019, 120, 6004-6014. [CrossRef]

39. Flonta, S.E.; Arena, S.; Pisacane, A.; Michieli, P.; Bardelli, A. Expression and Functional Regulation of Myoglobin in Epithelial Cancers. Am. J. Pathol. 2009, 175, 201-206. [CrossRef]

40. Bicker, A.; Nauth, T.; Gerst, D.; Aboouf, M.A.; Fandrey, J.; Kristiansen, G.; Gorr, T.A.; Hankeln, T. The Role of Myoglobin in Epithelial Cancers: Insights from Transcriptomics. Int. J. Mol. Med. 2020, 45, 385-400. [CrossRef]

41. Kristiansen, G.; Rose, M.; Geisler, C.; Fritzsche, F.R.; Gerhardt, J.; Lüke, C.; Ladhoff, A.-M.; Knüchel, R.; Dietel, M.; Moch, H.; et al. Endogenous Myoglobin in Human Breast Cancer Is a Hallmark of Luminal Cancer Phenotype. Br. J. Cancer 2010, 102, 1736-1745. [CrossRef] [PubMed]

42. Berry, D.A.; Cirrincione, C.; Henderson, I.C.; Citron, M.L.; Budman, D.R.; Goldstein, L.J.; Martino, S.; Perez, E.A.; Muss, H.B.; Norton, L.; et al. Estrogen-Receptor Status and Outcomes of Modern Chemotherapy for Patients With Node-Positive Breast Cancer. JAMA 2006, 295, 1658-1667. [CrossRef] [PubMed]

43. Faneyte, I.F.; Schrama, J.G.; Peterse, J.L.; Remijnse, P.L.; Rodenhuis, S.; van de Vijver, M.J. Breast Cancer Response to Neoadjuvant Chemotherapy: Predictive Markers and Relation with Outcome. Br. J. Cancer 2003, 88, 406-412. [CrossRef]

44. Solar Fernandez, V.; Cipolletti, M.; Ascenzi, P.; Marino, M.; Fiocchetti, M. Neuroglobin As Key Mediator in the 17 $\beta$-EstradiolInduced Antioxidant Cell Response to Oxidative Stress. Antioxid. Redox Signal. 2019, 32, 217-227. [CrossRef] [PubMed]

45. Fiocchetti, M.; Cipolletti, M.; Leone, S.; Naldini, A.; Carraro, F.; Giordano, D.; Verde, C.; Ascenzi, P.; Marino, M. Neuroglobin in Breast Cancer Cells: Effect of Hypoxia and Oxidative Stress on Protein Level, Localization, and Anti-Apoptotic Function. PLoS ONE 2016, 11, e0154959. [CrossRef] [PubMed] 